\title{
A study of hydrogen fuel impact on compression ignition engine performance
}

\author{
Evgeni Dimitrov ${ }^{1, *}$, Boyko Gigov ${ }^{1}$, Spas Pantchev ${ }^{1}$, Philip Michaylov ${ }^{1}$, and Mihail Peychev ${ }^{1}$ \\ ${ }^{1}$ Technical University - Sofia, Department of Combustion Engines, Automobile Engineering and Transport, Bulgaria
}

\begin{abstract}
In this paper, a dual-fuel compression ignition engine test bench is presented. In hydrogen-diesel fuel co-combustion conditions, the engine parameters are determined - performance: effective torque, effective power and mean effective pressure; fuel economy: fuel consumption and specific fuel consumption; toxicity: carbon monoxide, carbon dioxide, nitrogen oxides, hydrocarbons, and smoke emissions (opacity). The impact of hydrogen-diesel fuel mass ratio on the performance, toxicity and economy of the engine is studied by obtaining a series of hydrogen-diesel fuel ratio variation characteristics at constant engine speed and load. Improvement of the economical parameters of the engine and reduction of carbon dioxide concentration in exhaust gases is detected under operation with hydrogen gas fuel. Significant reduction of the exhaust gases opacity is observed. It is not clear what the impact of the quantity of hydrogen, injected in the engine, on the concentration of nitrogen oxides in the exhaust gases is.
\end{abstract}

\section{Introduction}

Today, internal combustion engines are thermal machines which have reached a very high level of perfection - in their design and technology, as in the process of their working cycle. However, two constantly growing problems are blocking their progress: a deepening energy crisis and excessive environment pollution.

The development of the diesel engine is associated with meeting the regulations for acceptable concentration of toxic components, particle emissions and greenhouse gases in the exhaust. It is widely known that the main reason for particle emissions, mostly free carbon in soot form, of a diesel engine is the non-homogenous nature of the air-fuel mixture. In this relation, the higher level of homogenization of the air-fuel mixture in the gas-diesel cycle is a prerequisite for a fundamental improvement of diesel engine emissions.

A gas-diesel cycle could be accomplished with many gas fuels: liquefied petroleum gas - LPG (mixture of propane and butane), compressed natural gas - $\mathrm{CNG}$ (methane), hydrogen $-\mathrm{H}_{2}$, etc. [1-4]. Hydrogen has a number of properties [5,6], which make it one of the most perspective alternative fuels for internal combustion engines:

- the lower heating value of hydrogen is on average by 2,8 times higher than that of gasoline and diesel fuel;

- the necessary energy for the ignition of hydrogen is a bit lower that the one necessary for hydrocarbon fuels;

- hydrogen has a very high rate of diffusion, due to which a practically homogenous hydrogen-air mixture can be achieved;

- hydrogen-air mixtures have very wide flammability boundaries- from air-fuel ratio of $\alpha=0,2$ to air-fuel ratio of $\alpha=10$;
- no greenhouse gases are produced during hydrogen combustion.

Two methods of achieving a gas-diesel cycle are possible. With the first one, external mixture formation, hydrogen is injected in the intake of the engine, where it mixes with the air, entering the engine. The second method consists of a direct injection of hydrogen in the cylinder - internal mixture formation [7]. Apart from the problems with hydrogen storage [8], and the lack of charge stations for it, both methods of organizing a gasdiesel cycle with hydrogen have to overcome a lot of problems, related to their practical application in vehicles.

The design of new fuel systems, hydrogen flow control systems and engine construction modification are needed for the accomplishment of a hydrogen gas-diesel cycle and internal mixture formation. Meanwhile, for the execution of a gas-diesel cycle with external mixture formation, an optimization of the mass fraction of hydrogen in the total fuel mass, entering the engine, is essential. With all parameters being constant, except for the quantity of hydrogen, the increase of hydrogen mass fraction leads to:

- improvement of engine economy $[9,10]$;

- reduction of the exhaust gases opacity and carbon dioxide concentration $[9,10]$;

- reduction of the engine volumetric efficiency due to the low density of hydrogen and the large volume of the intake;

- increase of the maximum in-cylinder pressure and temperature values [11-13], due to the higher of the flame front speed;

- high pressure rise rate $-d p / d \varphi$ during combustion $[11,14]$;

- an increase of nitrogen oxide and hydrocarbon concentration in the exhaust gases [15].

\footnotetext{
* Corresponding author: etzd@tu-sofia.bg
} 


\section{Purpose of the research}

In relation to the aforementioned facts the purpose of the research is the quantitative assessment of the impact of the hydrogen mass fraction (in percentage) in the total fuel mass, entering a diesel engine, on its performance during a gas-diesel cycle.

\section{Experimental setup}

A single cylinder, four stroke engine DV550 (Bulgaria) with air cooling is used for the purposes of the study. Several of the most important parameters of the engine are: bore $D=91,5 \mathrm{~mm}$; stroke $S=85 \mathrm{~mm}$; compression ratio $\varepsilon=17,5$; direct injection; nominal power $N_{e}=8 \mathrm{~kW}$ at engine speed $n=3000 \mathrm{~min}^{-1}$.

A schematic of the experimental setup is shown in Fig. 1. Engine 17 is connected to a direct current dynamometer "SAK 28-15", which is used to determine engine performance. Hydrogen is injected in the engine intake manifold under pressure $p_{H 2}=0,65$ bar, using a quick-acting gas valve. The pressure is reduced from 150 bar in the storage cylinder 18 to nominal pressure using a regulator valve 2 . The hydrogen mass flow is regulated by an electronic control system 7 , which is a product of cooperation between specialists of the "Department of Electrical Motion Automation Systems" and the "Department of Combustion Engines, Automobile Engineering and Transport" of the Technical University Sofia. The system guarantees manual control (via potentiometer) of the quick-acting gas valve, i.e. of hydrogen quantity. The volume flow of the hydrogen entering the engine is measured with a gas flow meter 3 , G4 type (Italy), connected between the regulator and the quick-acting gas valve. The accuracy of the hydrogen flow meter is $0,2 \mathrm{dm}^{3}$. A pressure gauge (with an accuracy of $5 \mathrm{kPa}$ ) and a type- $\mathrm{K}$ thermocouple connected to a digital thermometer $\left(1{ }^{\circ} \mathrm{C}\right.$ accuracy) are mounted in a separate chamber 4 leading to the gas flow meter. They are used to determine the temperature and pressure of the hydrogen entering the engine intake. The values of these parameters are used to calculate mass hydrogen consumption.

A volume flow meter 5, which operates by measuring the time necessary for a known quantity of liquid fuel to enter the engine, is used to determine the diesel fuel consumption. The flow meter is developed by the Department of Combustion Engines, Automobile Engineering and Transport of the Technical University Sofia and has an accuracy of $0,2 \mathrm{~cm}^{3}$.

The engine intake air flow is measured by a differential water pressure gauge and an orifice connected to an air receiver 12 . The differential pressure gauge readings have an accuracy of $1 \mathrm{~mm}$ water column.

The engine exhaust gas temperature is measured with a type- $\mathrm{K}$ thermocouple and a digital thermometer with an accuracy of $1{ }^{\circ} \mathrm{C}$. The thermocouple is mounted on the engine exhaust pipe, $100 \mathrm{~mm}$ away from the engine exhaust manifold flange.

The engine exhaust emissions are determined using a "Texa gasbox" gas analyser (Italy) 9. Apart from its other parameters, the gas analyser detects the following toxic components of the engine exhaust: carbon oxide $\mathrm{CO}$ ( $0,01 \%$ accuracy); hydrocarbons HC (1 ppm accuracy); nitrogen oxides $\mathrm{NO}_{\mathrm{x}}(5 \mathrm{ppm}$ accuracy); carbon dioxide $\mathrm{CO}_{2}\left(0,1 \%\right.$ accuracy); oxygen $\mathrm{O}_{2}(0,1 \%$ accuracy).

The exhaust gas opacity $R_{h}$ is measured using the "Hartridge" method with a "Tecnotest 495/1" smoke meter (Italy) - 1 with an accuracy of $0,1 \%$.

The engine combustion process parameters are registered with an "AVL Indiset 620" indicating system (Austria).

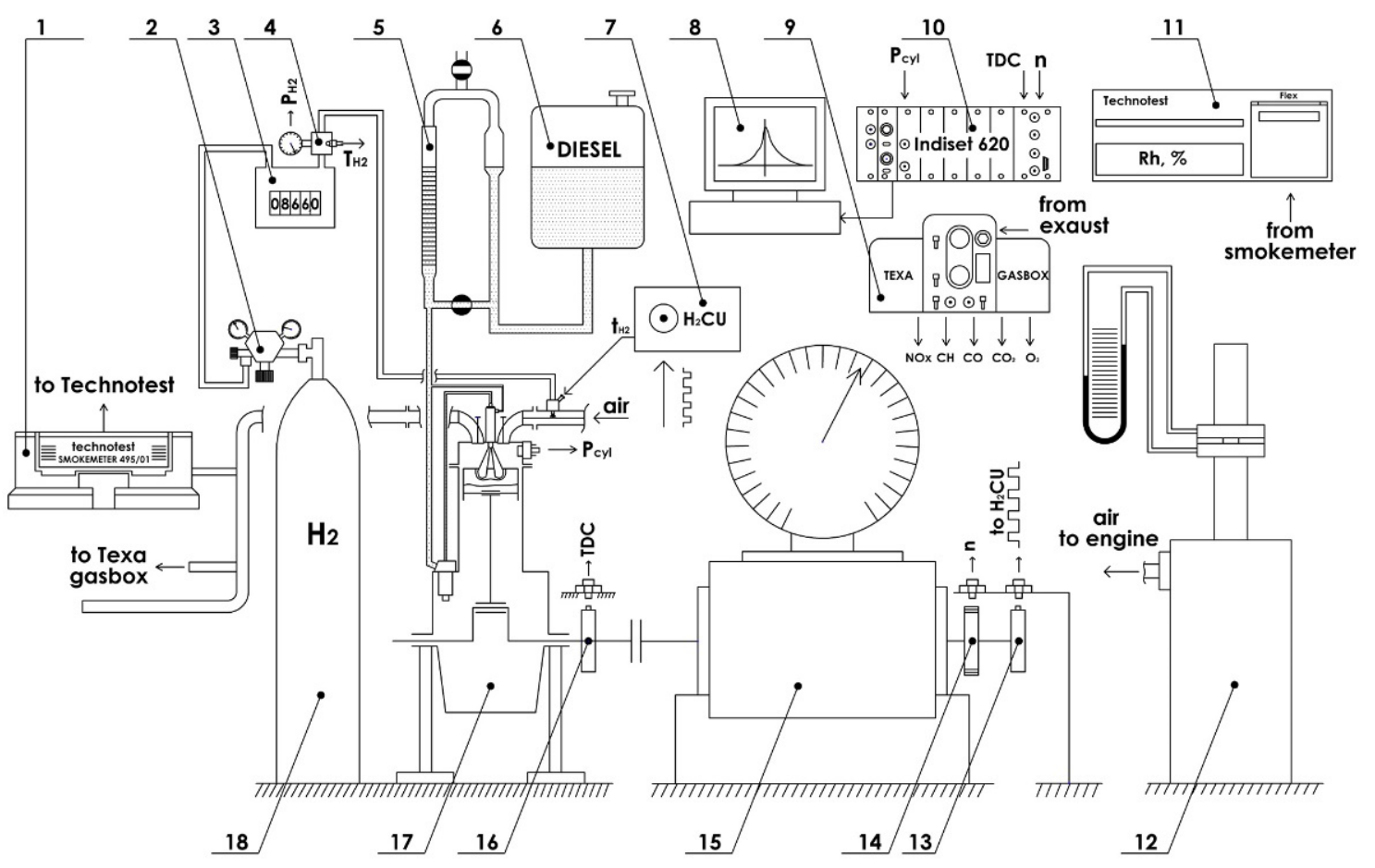

Fig.1. Schematic of the experimental setup. 


\section{Methodology of the study}

The gas-diesel cycle requires the diesel engine to work with two types of fuel in a certain ratio. Therefore, a mass fraction coefficient for each fuel has to be defined. For hydrogen and diesel fuel, these coefficients, $K_{\mathrm{H} 2}$ and $K_{D}$, respectively, equal:

$$
\begin{aligned}
K_{H_{2}} & =\left(\frac{B_{H_{2}}}{B_{h}}\right) \cdot 100, \% \\
K_{D} & =\left(\frac{B_{D}}{B_{h}}\right) \cdot 100, \%
\end{aligned}
$$

where $B_{H 2}$ is the hourly hydrogen consumption, $\mathrm{kg} / \mathrm{h}$; $B_{D}$ - the hourly diesel fuel consumption, $\mathrm{kg} / \mathrm{h}$; $B_{H}-$ the total hourly fuel consumption, $\mathrm{kg} / \mathrm{h}$.

The total fuel consumption can be obtained by the equation:

$$
B_{h}=B_{D}+B_{H_{2}}, \mathrm{~kg} / \mathrm{h}
$$

The effect of hydrogen on engine performance can be most precisely evaluated by comparing the load characteristics with diesel fuel with the load characteristics with constant hydrogen mass fraction (constant $K_{\mathrm{H} 2}$ ). Practically, this could be achieved by comparing the engine characteristics at constant rpm, constant $K_{\mathrm{H} 2}$ coefficient values and variable load.

Obtaining such characteristics directly, however, is associated with significant difficulties such as quickacting measurement devices which can allow for recording of the corresponding parameters in real time. In this respect, the characteristics mentioned above were generated in two stages. The first stage includes obtaining regulation characteristics with variable hydrogen content. These characteristics are obtained at constant speed ( $n=$ const) and constant mean effective pressure ( $p_{e}=$ const, dynamometer force $F_{B}=$ const) while varying the quantity of diesel fuel and hydrogen. The results are shown graphically as economical, ecological and other parameters as a function of the mass fraction of hydrogen in the total fuel mass, i.e. $K_{\mathrm{H} 2}$. The second stage includes determining (from the corresponding regulation characteristics) the engine parameters for a given speed and $K_{\mathrm{H} 2}$ coefficient. With the parameters calculated in this way, the load characteristics for a certain speed and hydrogen content are obtained.

Details related to the specific execution of the so described methodology could be found in a published paper of which some of the participants in the current research are co-authors [16].

\section{Results}

As mentioned above, the experimental engine is a singlecylinder engine. Such engines possess some distinctive features related to their balancing, optimal counterweight and flywheel dimensions [17]. Therefore, the experimental study is conducted in engine modes typical for the engine, without high-amplitude vibrations in the mounting points.
Some of the experimental results are shown in Figures 2-12, where the following symbols are additionally used:

- $b_{e}$ - brake specific fuel consumption, $\mathrm{g} / \mathrm{kWh}$;

- $\eta_{e}$ - brake thermal efficiency;

- $\eta_{v}$ - volumetric efficiency;

- $(d p / d \varphi)_{\max }-$ maximum in-cylinder pressure rise rate, bar/deg;

- $T_{\mathrm{EG}}-$ exhaust gas temperature, ${ }^{\circ} \mathrm{C}$.

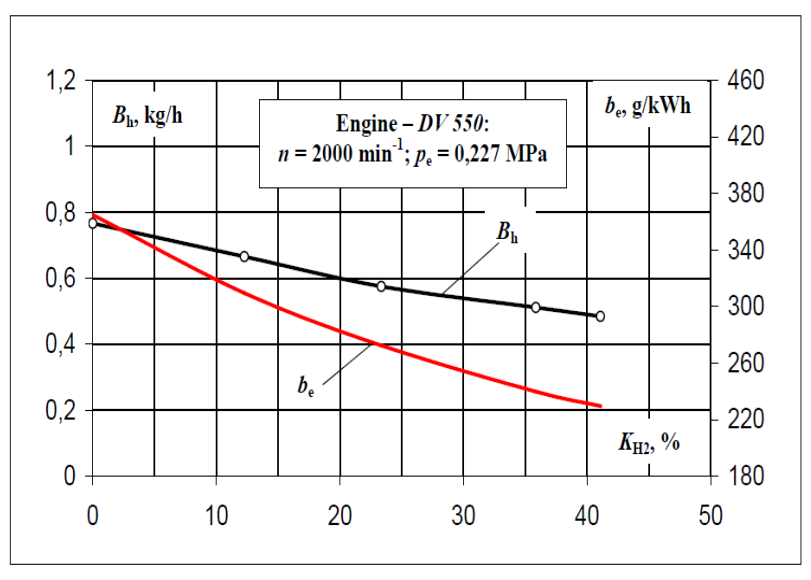

Fig.2. Variation of the economy of a $D V 550$ diesel engine, working on a gas-diesel cycle as a function of the mass fraction of hydrogen.

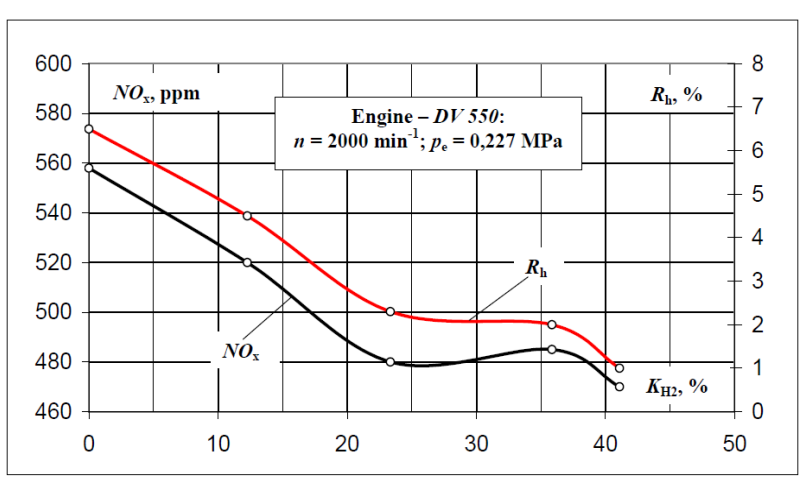

Fig.3. Variation of the nitrogen oxides concentration and the exhaust gases opacity of a $D V 550$ diesel engine, working on a gas-diesel cycle in function of the mass fraction of hydrogen.

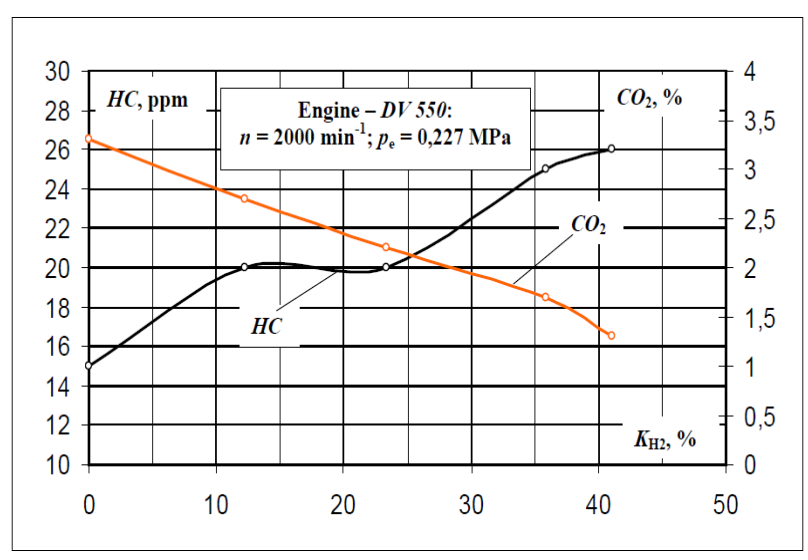

Fig.4. Variation of the hydrocarbons and carbon dioxide concentration in the exhaust gases of a $D V 550$ diesel engine, working on a gas-diesel cycle as a function of the mass fraction of hydrogen. 


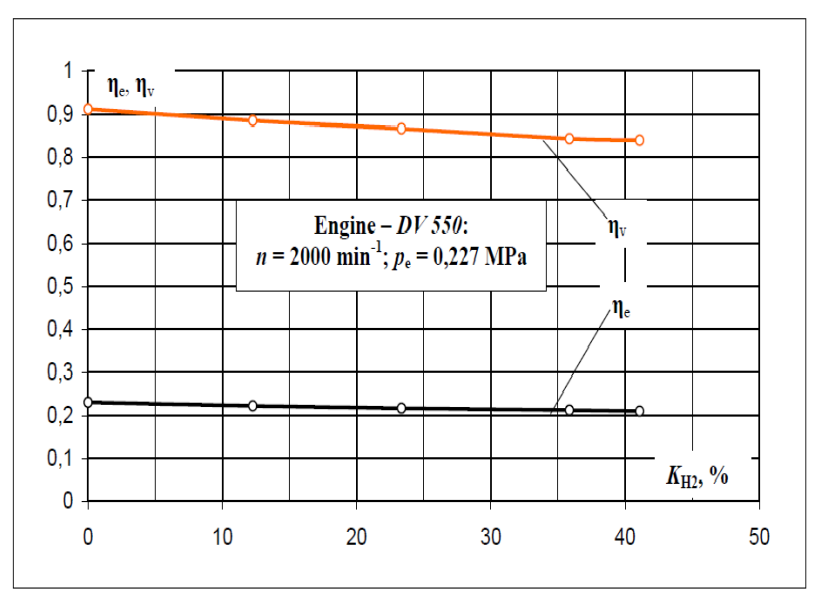

Fig.5. Variation of the brake thermal efficiency and the volumetric efficiency of a $D V 550$ diesel engine, working on a gas-diesel cycle as a function of the mass fraction of hydrogen.

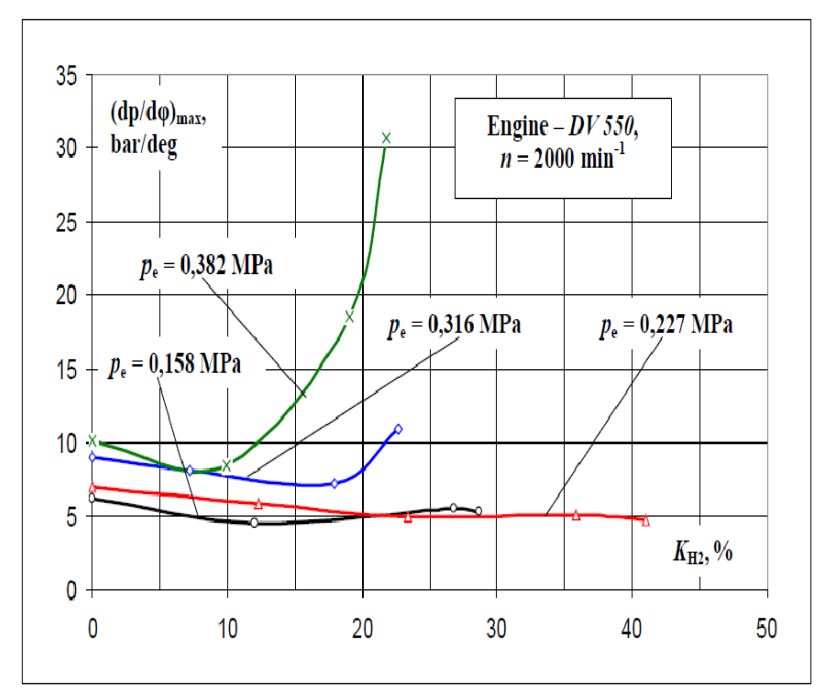

Fig.6. Variation of the maximum in-cylinder pressure rise rate in the cylinder of a $D V 550$ diesel engine, working on a gasdiesel cycle as a function of the mass fraction of hydrogen.

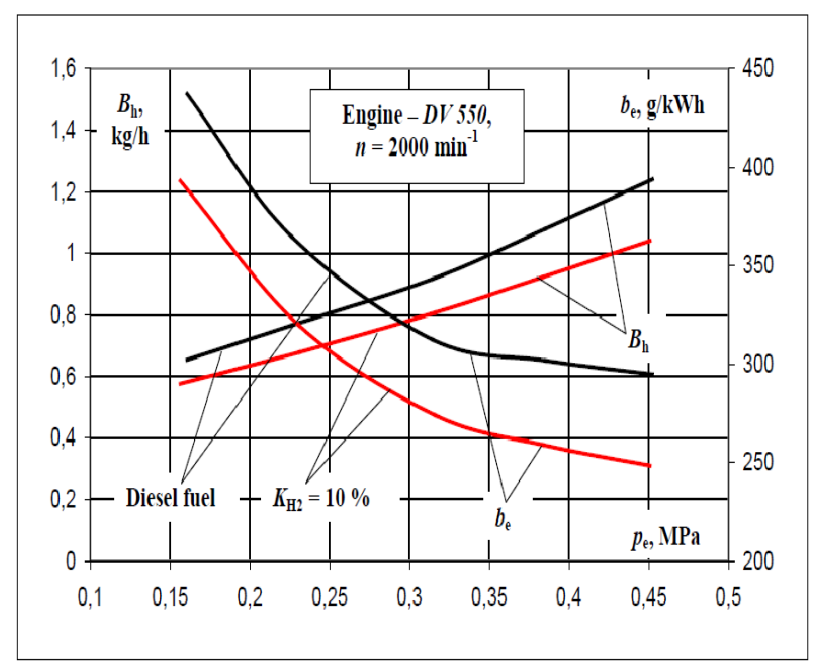

Fig.7. Comparison of the economical parameters of a $D V 550$ diesel engine at an engine speed of $2000 \mathrm{rpm}$ and variable load, running on: a diesel fuel and a gas-diesel cycle with hydrogen (dual fuel mode/diesel-fuel mixture) $-K_{H 2}=10 \%$.

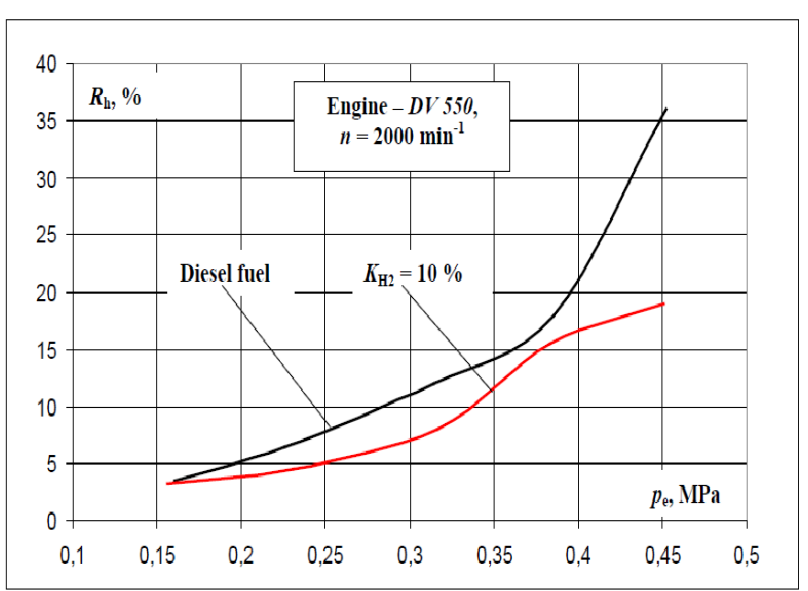

Fig.8. Comparison of the exhaust gas opacity of a $D V 550$ diesel engine at engine speed of $2000 \mathrm{rpm}$ and variable load, running on: a diesel fuel and a gas-diesel cycle with hydrogen (dual fuel mode/diesel-fuel mixture) $-K_{\mathrm{H} 2}=10 \%$.

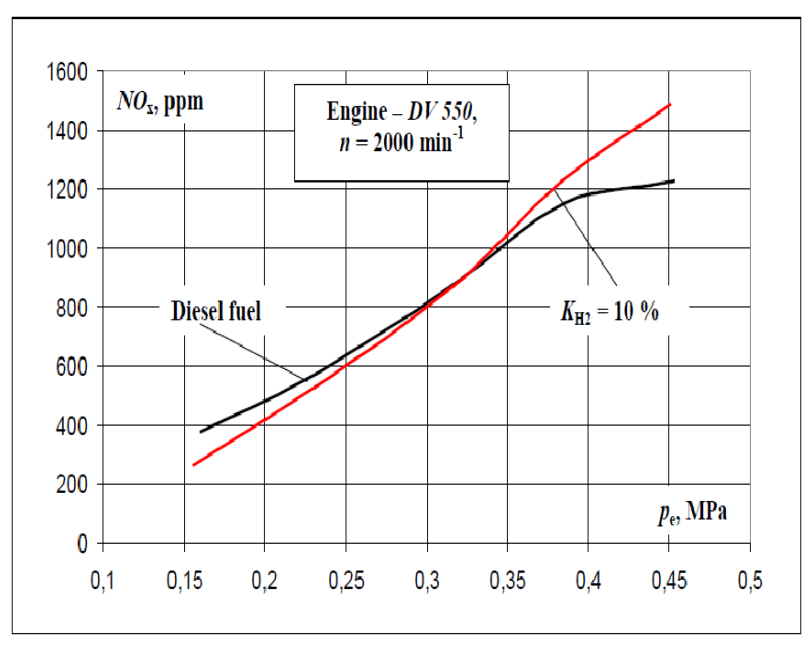

Fig.9. Comparison of the concentration of nitrogen oxides in the exhaust gases of a $D V 550$ diesel engine at engine speed of $2000 \mathrm{rpm}$ and variable load, running on: a diesel fuel and a gas- diesel cycle with hydrogen (dual fuel mode/diesel-fuel mixture) $-K_{\mathrm{H} 2}=10 \%$.

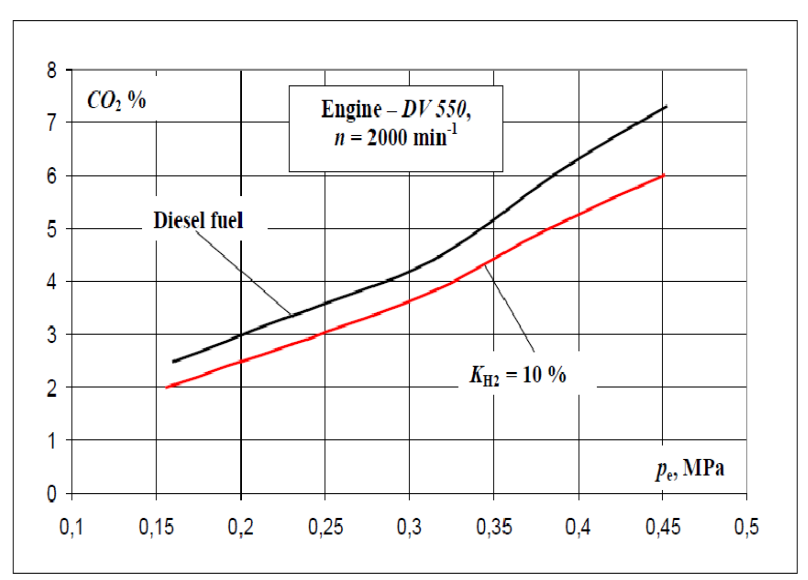

Fig.10. Comparison of the concentration of carbon dioxide in the exhaust gases of a $D V 550$ diesel engine at engine speed of $2000 \mathrm{rpm}$ and variable load, running on: a diesel fuel and a gas-diesel cycle with hydrogen (dual fuel mode/diesel-fuel mixture) $-K_{\mathrm{H} 2}=10 \%$. 


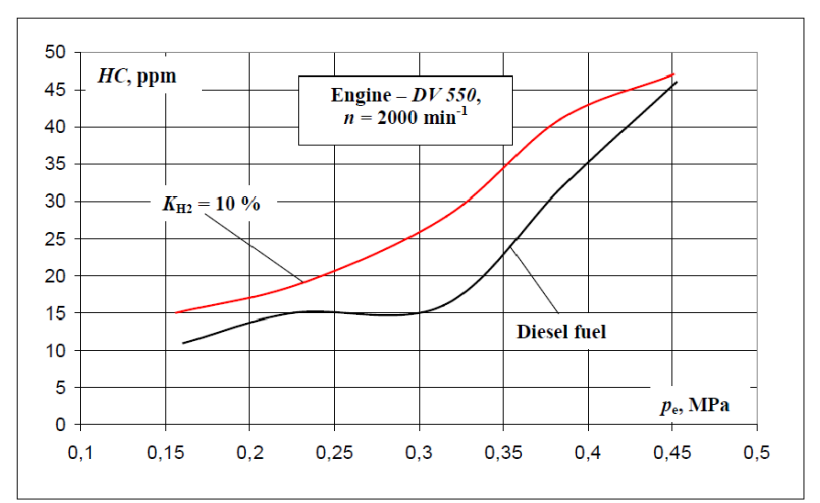

Fig.11. Comparison of the concentration of hydrocarbons in the exhaust gases of a $D V 550$ diesel engine at engine speed of $2000 \mathrm{rpm}$ and variable load, running on: diesel fuel and gasdiesel cycle with hydrogen (dual fuel mode/diesel-fuel mixture) $-K_{\mathrm{H} 2}=10 \%$.

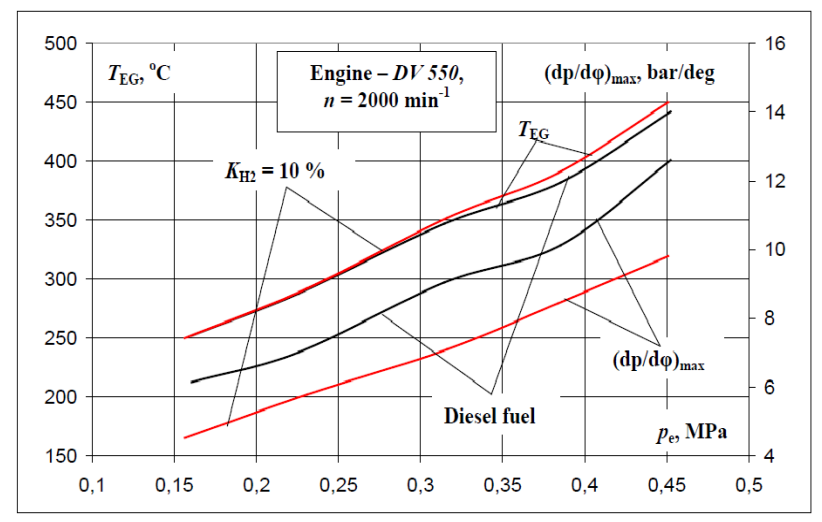

Fig.12. Comparison of the exhaust gas temperature and the maximum in-cylinder pressure rise rate of a diesel engine DV 550 at $2000 \mathrm{rpm}$ and variable load, running on: a diesel fuel and gas-diesel cycle with hydrogen (dual fuel mode/dieselfuel mixture) $-K_{\mathrm{H} 2}=10 \%$.

The analysis of the experimental results obtained from the examination of a $D V 550$ diesel engine running on dual fuel mode showed the following:

1. A decrease in fuel consumption and brake specific fuel consumption is observed in every engine mode with the engine operating in a gas-diesel cycle as compared to the operation on standard diesel fuel. From a quantitative point of view, the percentage drop of $B_{h}$ and $b_{\mathrm{e}}$ is proportional to the $K_{\mathrm{H} 2}$ coefficient. For example, fuel consumption and brake specific fuel consumption of an engine working on a gas-diesel cycle with $K_{\mathrm{H} 2}=41,08 \%$ are $37 \%$ lower than those of an engine working on diesel fuel. The improvement in the engine economical parameters is due to the higher value of the lower heating value of hydrogen as compared to that of the diesel fuel.

2. A considerable drop in exhaust gas opacity during engine operation in a gas-diesel cycle with hydrogen is present. In some engine modes, at loads up to $30 \%$ and hydrogen mass fraction higher than $20 \%\left(K_{\mathrm{H} 2}>20 \%\right)$, the exhaust gas opacity during engine operation on a gasdiesel cycle with hydrogen is 6 to 7 times lower than the opacity during engine operation on diesel fuel. For the load characteristics at $2000 \mathrm{rpm}$, the exhaust gas opacity in a gas-diesel cycle for $K_{\mathrm{H} 2}=10 \%$ is lower by $26,75 \%$ on average than in a diesel fuel cycle under the same conditions and lower by $41,42 \%$ on average for $K_{\mathrm{H} 2}=14 \%$. The decrease of the exhaust opacity of the engine while operating in a gas-diesel cycle with hydrogen is mainly due to the high level of homogenization of the air-fuel mixture. The lower mass fraction of carbon in the total fuel mass, however, has a positive impact on opacity too.

3. The impact of the hydrogen mass fraction on the concentration of nitrogen oxides in the engine exhaust during operation on a gas-diesel cycle is not clear. With engine working in a gas-diesel cycle with hydrogen mass fraction higher than $25 \%\left(K_{\mathrm{H} 2}>25 \%\right)$ and load of up to $30 \%$, an average reduction of $23,7 \%$ in the concentration of nitrogen oxides is observed. In the range of variation of the hydrogen mass fraction from 10 to $20 \%\left(K_{\mathrm{H} 2}=10 \%\right.$ to $K_{\mathrm{H} 2}=20 \%$ ) and engine working in a gas-diesel cycle with a load of over $50 \%$, an increase of the nitrogen oxides concentration in the exhaust gases of $57,8 \%$ on average (as compared to the operation on diesel fuel) is observed. The impact of the hydrogen mass fraction on nitrogen oxides concentration could be explained with the variation of the engine exhaust temperature and the reduction of the total air-fuel ratio during a gas-diesel cycle operation;

4. Carbon dioxide concentration in the engine exhaust in a gas-diesel cycle with hydrogen decreases significantly. The reduction amounts to $25,75 \%$ on average in every engine mode. As mentioned above, the reduced concentration of carbon dioxide in the engine exhaust is due to the lower mass fraction of carbon in the total fuel mass;

5. An increase of hydrocarbon concentration by $28,5 \%$ on average is observed in all engine modes in gas-diesel cycle, as compared to the operation on diesel fuel. The hydrocarbon increase in the exhaust is due to the reduced air-fuel ratio in a gas-diesel cycle with hydrogen;

6 . The engine exhaust gas temperature during a gasdiesel cycle operation changes similarly to the concentration of nitrogen oxides in the exhaust gases. The differences in exhaust gas temperature of the engine working on a gas-diesel cycle (for all values of the $K_{\mathrm{H} 2}$ coefficient) and diesel fuel are insignificant for loads of up to $30 \%$. An increase of $20^{\circ} \mathrm{C}$ on average in the exhaust gas temperature is observed with the engine working on a gas-diesel cycle with $K_{\mathrm{H} 2}>10 \%$ and with loads higher than $50 \%$ as compared to the operation on diesel fuel;

7. The engine volumetric efficiency $\eta_{v}$ decreases in a gas-diesel cycle with hydrogen. The reduction is by up to $9 \%$ for loads higher than $50 \%$ and $K_{\mathrm{H} 2}$ values higher than $15 \%$. The decreased mass air-fuel mixture intake is an expected phenomenon due to the low density of hydrogen injected in the engine intake manifold. The impact of the hydrogen mass entering the engine on its brake thermal efficiency $\eta_{e}$ is insignificant;

8. The diesel knock correlated to the maximum in cylinder pressure rise rate $(d p / d \varphi)_{\max }$ also changes insignificantly as function of the mass of hydrogen fed into the engine. With an engine working on a gas-diesel cycle and load up to $30 \%$, irrespective of the $K_{\mathrm{H} 2}$ coefficient values, a reduction of $(d p / d \varphi)_{\max }$ (reaching $30 \%$ for some modes) is observed. For loads higher than $50 \%$ and $K_{\mathrm{H} 2}$ values over $15 \%$, a gas-diesel cycle 
operation is associated with dangerously high maximum in-cylinder pressure rise rate reaching $25 \mathrm{bar} / \mathrm{deg}$. Therefore, the load characteristics is shown for $K_{\mathrm{H} 2}=10 \%$. The high values of $(d p / d \varphi)_{\max }$ when operating on a gas-diesel cycle at the abovementioned modes are undoubtedly due to the very high speeds of the hydrogen air-mixture flame front.

\section{Conclusions}

The analysis of the experimental study results leads to the following conclusions:

- The realization of a gas-diesel cycle with hydrogen results in an improvement of the economical parameters of the engine in its whole working range;

- The engine operation on a gas-diesel cycle guarantees significant reduction of the exhaust gas opacity and carbon dioxide concentration;

- A decrease of the nitrogen oxide concentration and decreased diesel knock is achieved during engine operation on a gas-diesel cycle with hydrogen and loads of up to $30 \%$;

- For hydrogen mass fraction higher than $10 \%$ and with the engine working on a gas-diesel cycle at loads higher than $50 \%$, the diesel knock and the nitrogen oxide concentration in the exhaust rise significantly;

- The diesel engine operation on a gas-diesel cycle leads to increased hydrocarbon concentration in the exhaust and reduced volumetric efficiency for external mixture formation.

In conclusion, we can state that the implementation of a gas-diesel cycle with hydrogen and external mixture formation is a promising method for improving the ecological and economical parameters of the diesel internal combustion engines. With effective and safe hydrogen storage systems, this method can be adopted for transport diesel engines as it does not require changes in their design.

\section{References}

1. E. Uludamar, Effect of hydroxy and hydrogen gas addition on diesel engine fuelled with microalgae biodiesel, International journal of hydrogen energy, (in press) (2018)

2. H. Arat, M. Baltacioglu, M. Özcanli, K. Aydin, Effect of using Hydroxy-CNG fuel mixtures in a nonmodified diesel engine by substitution of diesel fuel, International journal of hydrogen energy, 41(19), 8354-8363 (2016)

3. G. Belgiornoa, G. Blasioa, C. Beatricea, Parametric study and optimization of the main engine calibration parameters and compression ratio of a methane-diesel dual fuel engine, Fuel, 222, 821-840 (2018)

4. B. Ashok, S. Ashok, C. Kumar, LPG diesel dual fuel engine - A critical review, Alexandria Engineering Journal, 54(2), 105-126 (2015)

5. H. Wu, Z. Wu, Study on combustion characteristics and emissions of diesel-hydrogen mixtures by using energy-share method in a diesel engine, Applied Thermal Engineering, 42, 154-162 (2012)
6. M. Ciniviz, H. Köse, Hydrogen use in internal combustion engine: A review, International Journal of Automotive Engineering and Technologies, 1(1), 1-15 (2012)

7. J. Antunes, R. Mikalsen, A. Roskilly, An experimental study of a direct injection compression ignition hydrogen engine, International journal of hydrogen energy, 34(15), 6516-6522 (2009)

8. G. Berry, A. Pasternak, G. Rambach, J. Smith, R. Schock, Hydrogen as future transportation fuel, Energy, 21(4), 289-303 (1996)

9. H. Koten, Hydrogen effects on diesel engine performance and emissions, International journal of hydrogen energy, 43(22), 10511-10519 (2018)

10. I. Mirica, C. Pana, N. Negurescu, A. Cernat, C. Nutu, Experimental studys of the hydrogen addition effects on diesel engine performance, IOP Conf. Series: Materials Science and Engineering, 147(1) (2016)

11. N. Saravanan, G. Nagarajan, G. Sanjay, C. Dhanasekaran, K. Kalaiselvan, Combustion analysis on a DI diesel engine with hydrogen in dual fuel mode, Fuel, 87(17-18), 3591-3599 (2008)

12. P. Dimitriou, M. Kumar, T. Tsujimura, Y. Suzuki, Combustion and emission characteristics of a hydrogen-diesel dual-fuel engine, International journal of hydrogen energy, 43(29), 13605-13617 (2018)

13. T. Tsujimura, Y. Suzuki, The utilization of hydrogen in hydrogen/diesel dual fuel engine, International journal of hydrogen energy, 42(19), 14019-14029 (2017)

14. I. Mirica, A. Cernat, C. Pana, N. Negurescu, C. Nutu, Performance comparison between hydrogen and diesel fuel fuelled compression ignition engine, U.P.B. Sci. Bull., Series D, 77(4), 217-228 (2015)

15. Y. Karagöz, İ. Guler, T. Sandalcı, L. Yüksek, A. Dalkılıç, Effect of hydrogen enrichment on combustion characteristics, emissions and performance of a diesel engine, International journal of hydrogen energy, 41(1), 656-665 (2016)

16. E. Dimitrov, A. Tashev, S. Pantchev, Methodology for Experimental Study of the Impact of Gaseous Fuels on the Performance of the Diesel Engine Operating on Gas-Diesel Cycle, BulTrans-2015 Proceedings, 103107 (2015)

17. N. Pavlov, Numerical simulation on the vibration of a test bed with Engine with dual mass flywheel, International scientific journal Trans Motauto World, 3(1), 49-51 (2018) 